\title{
Quantifying the vertical distribution pattern of land-use conversion in the loess hilly region of northern Shaanxi Province 1995-2015
}

\author{
CAO Zhi ${ }^{1,2},{ }^{*}$ LI Yurui ${ }^{1,2}$, LIU Zhengjia ${ }^{1,2}$, YANG Lingfan ${ }^{3}$ \\ 1. Institute of Geographic Sciences and Natural Resources Research, CAS, Beijing 100101, China; \\ 2. Center for Assessment and Research on Targeted Poverty Alleviation, CAS, Beijing 100101, China; \\ 3. Faculty of Geographical Sciences, Beijing Normal University, Beijing 100875, China
}

\begin{abstract}
The mountainous and hilly region plays an important role in ecological safety and production in China. However, recent studies have poorly characterized the parallel structure of land use in the valleys of the mountainous and hilly region using topographic factors (e.g. elevation, slope, aspect). Here, the loess hilly region of northern Shaanxi Province is used as a representative case area to analyze the vertical distribution pattern of land-use conversion using the relative elevation concept and the HAND index. The differences in the vertical structure of land-use conversion between absolute elevation and relative elevation were compared. We found that the classifications of absolute and relative elevation had similar proportions of each relative elevation grade in each absolute elevation grade. Cropland, woodland, and grassland were distributed evenly in each grade of absolute/relative elevation, while water body, built-up land and unused land were more likely to spread in low grades of relative elevation than those of absolute elevation. The land-use conversion (i.e. loss of cropland and gain in woodland and built-up land) showed an apparently stepped distribution with relative elevation classification, suitable for revealing vertical distributions of land-use conversion in the loess hilly region. Cropland transformed to woodland was mainly distributed in high grade of relative elevation, decreasing with a decrease in grades, while built-up land transformed from cropland and grassland was mainly distributed in low grade of relative elevation, decreasing with increases in grades. The grade of relative elevation where cropland transformed to woodland descended with the implementation of the Grain for Green Project. Our results suggest that it is better to analyze the vertical distribution of land-use conversion with relative elevation classification in hilly regions.
\end{abstract}

Keywords: land use change; vertical distribution pattern; topographic factors; HAND (Height above the Nearest Drainage); loess hilly region; northern Shaanxi Province

Received: 2018-07-20 Accepted: 2018-12-20

Foundation: National Key Research and Development Program of China, No.2017YFC0504701; National Natural Science Foundation of China, No.41801175; Postdoctoral Science Foundation of China, No.2018M631558

Author: Cao Zhi, PhD, specialized in land science and rural development. E-mail: caoz.14b@igsnrr.ac.cn

"Corresponding author: Li Yurui, PhD and Associate Professor, specialized in rural geography and land engineering. E-mail: liyr@igsnrr.ac.cn 


\section{Introduction}

Land use/land cover play important roles in understanding the interactions of human activity with the environment (Kumar et al., 2012; Liu et al., 2014; Liu, 2018). Furthermore, land use/land cover change (LUCC) is a popular topic in global ecological change, land-use allocation, and environment research (Liu et al., 2018a). Topics include spatial distribution and changes, causes and results, feedback mechanism with human activities, and optimal allocation of land use by policy makers (Liu and Li, 2017; Liu et al., 2017; Chang et al., 2018). In China, mountainous and hilly regions account for some $70 \%$ of national territorial area (Huang, 1986). These areas are also the production base for commercial crops, forest products, Chinese herbal medicines, green agricultural products, and grass and animal products. They also assume the responsibility for protecting gene, species, ecosystem, and landscape diversity, sheltering ecological safety, and the sustainable development of plain regions and cities across China. Therefore, research on LUCC in mountainous and hilly regions should be a priority.

Vertical zonality is a major feature of mountainous and hilly regions. Elevation, which affects precipitation, temperature, development space, and accessibility, has an important impact on the type, intensity, and density of human activities. Current infrastructure, economic activity, investments, and settlements are generally found in the low elevations of mountainous and hilly regions, while higher elevations are dominated by natural landscapes and are affected less by human activities. Classification of topographic factors is the method commonly adopted to indicate the vertical distribution and variation of land use. The topographic factors include elevation, slope, aspect and the Topographic Wetness Index (TWI), useful for revealing the vertical distribution of land use (Reis, 2008; Han and Jia, 2010; Park et al., 2011; Zhang et al., 2012; Li et al., 2016). However, we should note that in mountainous and hilly regions the development status and land use patterns in the upstream and downstream of gullies are usually similar in a given area and elevation range. The vertical distribution of land use in the upstream or downstream regions always presents some parallel structure relative to valleys, with grass and forest on the upper slope and settlements on the lower slope. Therefore, a relative elevation index, such as the Height above the Nearest Drainage (HAND) index, reflecting the height from valley, may be more useful if coupled with land use. The HAND index, reflecting the relative vertical flowpath distances to the nearest drainages, accurately expresses the concept of "relative elevation" (Renno et al., 2008; Nobre et al., 2011). This index is widely applied in hydrology, but has been rarely used in a coupled analysis with land use (de Lollo et al., 2019). Therefore, we employed this index to indicate relative elevation and as a means with which to analyze the vertical distribution of land use.

The loess hilly region of northern Shaanxi Province is a core area of the Loess Plateau in China, which is representative of mountainous and hilly regions. The arid and semi-arid continental monsoonal climate, thick and loose loess layer and unsustainable human activities have made this area the most seriously soil eroded region in China and possibly even globally, forming a fragmented landform of gullies and hummocks (Liu et al., 2015; Cao et al., 2018). To control soil erosion, a range of projects promoting different strategies and measures has been implemented since 1949, such as comprehensive management of small watersheds and the Grain for Green Project (GGP), with distinct effects on ecological resto- 
ration (Lü et al., 2012; Chen et al., 2015; Wang et al., 2015). The combination of representative topography, need for continued study of a fragile environment, and continued LUCC make the loess hilly region of northern Shaanxi an ideal study location for coupled analysis including relative elevation and LUCC. Recent studies have analyzed land-use conversion in the Loess Plateau using elevation and slope alone (Zhang et al., 2012; Li et al., 2016). On the whole, it is valuable to explore the vertical distribution pattern of land-use conversion in this area based on relative elevation.

The main objective of this study is to analyze the vertical distribution pattern of land-use conversion in the loess hilly region of northern Shaanxi based on relative elevation classification. The specific aims are to (1) compare vertical distribution patterns of absolute elevation and those of relative elevation, (2) compare vertical distribution patterns of land use with absolute elevation and those with relative elevation, (3) analyze land-use conversion without elevation, and (4) compare land-use conversion with absolute elevation and those with relative elevation to reveal the vertical distribution pattern of land-use conversion and verify the value of researching land-use conversion using relative elevation.

\section{Methodology}

\subsection{Study area}

The loess hilly region of northern Shaanxi Province covers the northern Shaanxi region, ex-

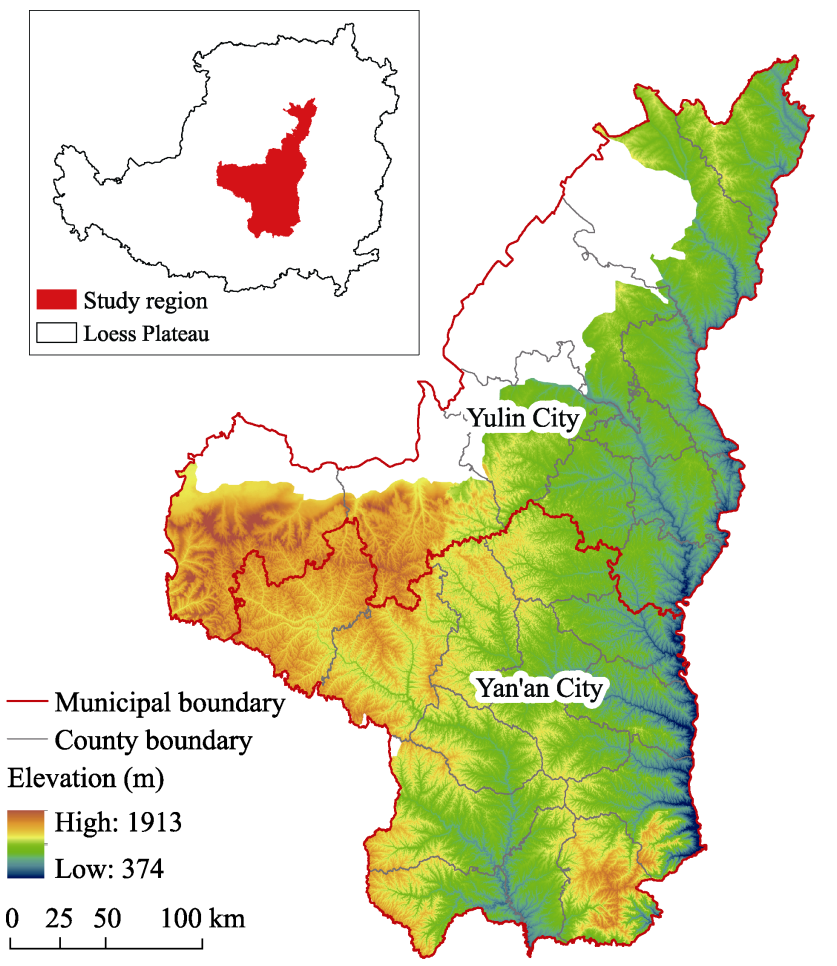

Figure 1 The digital elevation map of the loess hilly region in northern Shaanxi Province cluding the Mu Us Sandy Land ( $\mathrm{Li}$ et al., 2017) but including all of Yan'an City and part of Yulin City. This region covers an area of some $66,000 \mathrm{~km}^{2}$ in the middle reaches of China's Yellow River, accounting for $32.28 \%$ of Shaanxi's land area. It is known as the core area of China's Loess Plateau, south of the $\mathrm{Mu}$ Us Sandy Land and north of the Guanzhong Basin (Figure 1). The geomorphology of this area includes Loess Tableland, Loess Ridge, Loess Hill, and the transitional zones among them (Zhou et al., 2010). The area has an altitude between $374 \mathrm{~m}$ and $1913 \mathrm{~m}$, and the terrain of the northwest and west is higher than that of the southeast and east. It belongs to the arid and semi-arid continental monsoonal climate in the temperate zone, with annual mean tempera- 
tures ranging from 7 to $12^{\circ} \mathrm{C}$ and annual precipitation ranging from 350 to $600 \mathrm{~mm}$ (Bai et al., 2014). Temperature and precipitation decrease from the southeast to the northwest, and the precipitation varies seasonally and annually, with $60 \%-70 \%$ of the annual total falling in the rainy season from June to September in the form of high-intensity rainstorms, with a relative variation of 20-30\% (Lü et al., 2012; Li and Lü, 2015; Liu et al., 2019).

\subsection{Data source and processing}

Land use datasets used in this study were China's Land-Use/cover Datasets (CLUDs), provided by the Data Center for Resources and Environmental Sciences, Chinese Academy of Sciences (RESDC) (http://www.resdc.cn). The CLUDs were produced from interpreting Landsat TM images using the human-computer interactive interpretation method based on geographic knowledge (Liu et al., 2003; Liu et al., 2010; Ning et al., 2018). This study used the CLUDs' raster data for the loess hilly region of northern Shaanxi in 1995, 2000, 2005, 2010 , and 2015 with a spatial resolution of $30 \times 30 \mathrm{~m}$.

The terrain data were Advanced Spaceborne Thermal Emission and Reflection Radiometer (ASTER) Global Digital Elevation Model (GDEM) Version 2 products, obtained from the website of the USGS (United States Geological Survey) Earth Explorer (EE) (https://earthexplorer.usgs.gov/). The pixel size of the ASTER GDEM data is 1 arc-second (approximately $30 \mathrm{~m}$ at the equator). For consistency with the spatial resolution of land use datasets, the ASTER GDEM data were resampled using the Raster Processing toolset in ArcGIS 10.4. Based on the resampled DEM data, the valley lines and ridge lines were extracted using the Hydrology toolset and converted into raster using the To Raster toolset in ArcGIS 10.4 (Tang and Yang, 2015).

\subsection{Research methods}

This study adopted the HAND index to calculate the relative elevation of the loess hilly region using the DEM data. The HAND index reflects the relative vertical flowpath distances to the nearest drainages/valleys (Renno et al., 2008; Nobre et al., 2011). The flow path was calculated using the D-infinity flow model that defines flow direction as a vector along the direction of the steepest downward slope on eight triangular facets centered at each grid cell (Tarboton, 1997; Tesfa et al., 2011). Figure 2 shows the schematic of relative elevation calculation method. With this schematic, the relative elevation could be interpreted as the vertical flow distance from a point on the slope tracing down to a designated valley point defined by D-infinity flow model. The relative elevation of the study area was extracted using the AutoFuzSlpPos algorithm (https: // github. com//reis2415/AutoFuzSlpPos), which was integrated with the HAND function (Qin et

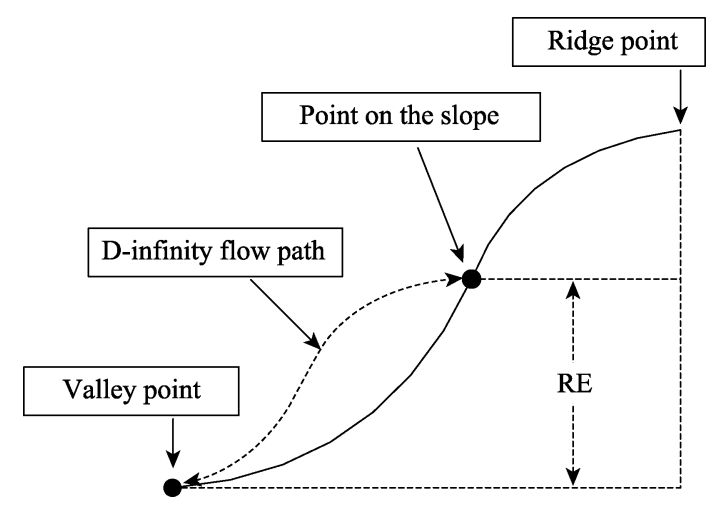

Figure 2 The schematic of relative elevation (RE) calculation method 
al., 2009; Zhu et al., 2018; Qin et al., 2018).

\section{Results and analysis}

\subsection{Patterns of absolute and relative elevation}

In this study, the number of grids was calculated for different absolute elevations; the number of grids exhibited an approximate normal distribution with elevation (Figure 3a). The number of grids below $750 \mathrm{~m}$ changed slowly, increased rapidly above $750 \mathrm{~m}$, and then increased slower above $1050 \mathrm{~m}$ than that between $750 \mathrm{~m}$ and $1050 \mathrm{~m}$ until the number of grids peaked at about $1120 \mathrm{~m}$. The numbers of grids subsequently lowered, although discontinuously, with increases in absolute elevation, and showed minor peaks at 1350-1400 m and 1450-1550 m. Different from the results for absolute elevation, the number of grids dropped almost continuously with increases in relative elevation with a decline below about $25 \mathrm{~m}$ and increase at about 25-70 $\mathrm{m}$ (Figure $3 \mathrm{~b}$ ). Then, the number of grids presented a rapid decrease between 70-200 $\mathrm{m}$ and reached a lower level above $200 \mathrm{~m}$.

An important aspect of exploring the relationships between land use and elevation is dividing absolute/relative elevation into grades. To compare the results between absolute elevation and relative elevation classification, the absolute/relative elevation was divided into five grades shown on the map (Figure 4). In the figure, the Quantile Classification method in ArcGIS software was used to obtain groups with roughly an equal number/area. Areas with
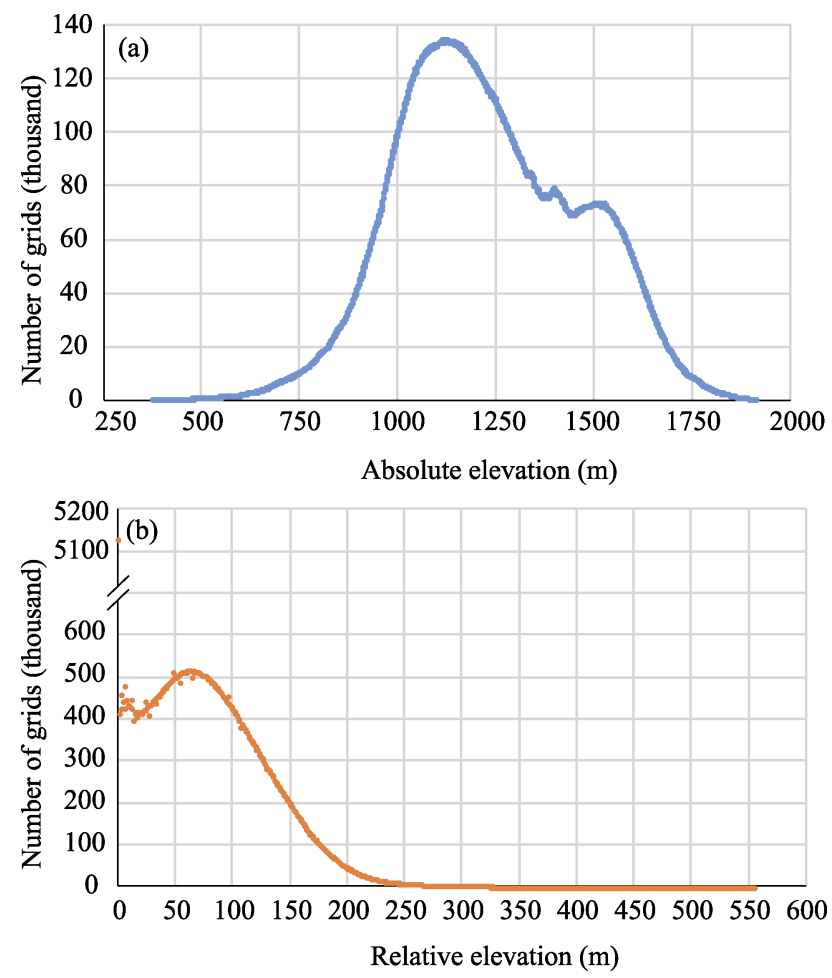

Figure 3 Statistical characteristics of grid-based absolute elevation and relative elevation in the loess hilly region of northern Shaanxi Province an absolute elevation classification presented higher in the west and lower in the east, and valleys showed nested distributions (Figure 4a). The difference between absolute elevation classification and relative elevation classification was that the latter presented higher valleys concentrated in the northwestern and eastern parts of Yan'an and lower valleys concentrated in most northern part of Yulin (Figure 4b). Different grades of relative elevation showed a parallel distribution, in much clearer detail than that revealed by abstalble ellepraticides the results of overlaying the classifications of absolute elevation and relative elevation. Each grade of absolute elevation had almost 
the same proportion of grades of relative elevation. In detail, the first grade of absolute elevation had a little more proportion of the first grade of relative elevation, while the fifth grade had a little more proportion of the fifth grade of relative elevation. In addition, the second and third grades of absolute elevation had a little more proportion of the second and third grades of relative elevation, while the fourth grade had a little more proportion of the fourth and fifth grades of relative elevation.

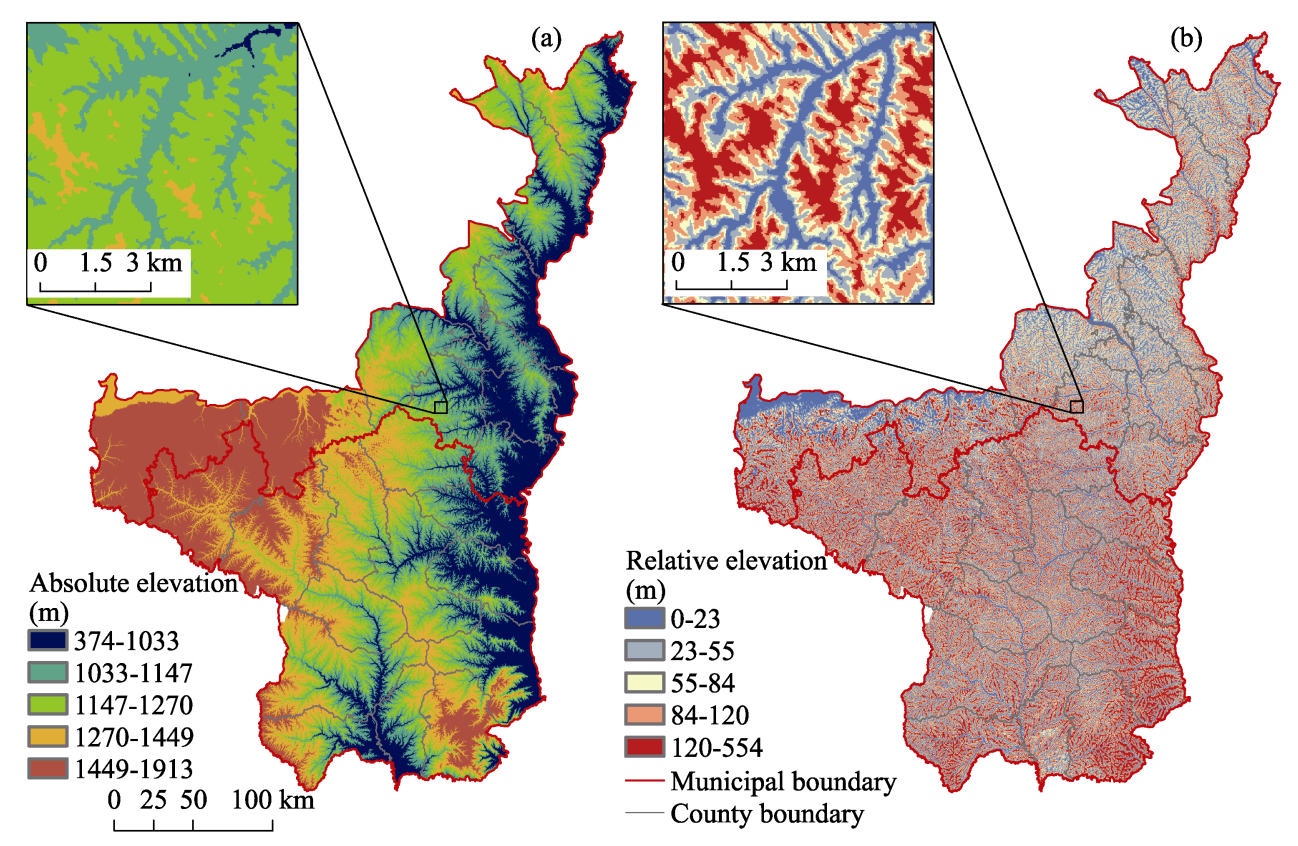

Figure 4 Patterns of grid-based absolute elevation and relative elevation in the loess hilly region of northern Shaanxi Province

Table 1 Cross matrix between different classifications of absolute elevation (AE) and relative elevation (RE) in the loess hilly region of northern Shaanxi Province

\begin{tabular}{|c|c|c|c|c|c|c|}
\hline \multirow{2}{*}{$\begin{array}{c}\text { Absolute } \\
\text { elevation (m) }\end{array}$} & \multicolumn{5}{|c|}{ Relative elevation (m, \%) } & \multirow{2}{*}{$\begin{array}{l}\text { Total } \\
\text { (AE) }\end{array}$} \\
\hline & $0-23$ & $23-55$ & $55-84$ & $84-120$ & $120-554$ & \\
\hline $374-1033$ & 6.35 & 4.55 & 3.62 & 3.05 & 2.51 & 20.09 \\
\hline $1033-1147$ & 4.00 & 4.85 & 4.61 & 3.86 & 2.73 & 20.04 \\
\hline $1147-1270$ & 3.46 & 4.49 & 4.57 & 4.28 & 3.30 & 20.09 \\
\hline $1270-1449$ & 3.71 & 3.39 & 3.79 & 4.49 & 4.56 & 19.93 \\
\hline $1449-1913$ & 2.78 & 3.10 & 3.28 & 4.23 & 6.46 & 19.86 \\
\hline Total (RE) & 20.30 & 20.37 & 19.87 & 19.90 & 19.56 & 100.00 \\
\hline
\end{tabular}

\subsection{Patterns of land use with absolute elevation and relative elevation}

According to the published datasets, the dominant land use types were grassland, cropland and woodland, accounting for $43.26 \%, 34.07 \%$ and $15.23 \%$ of total area, respectively, in 
2015. Grassland and cropland were scattered throughout the region, while woodland was concentrated in the south.

The land use structure for different classifications of absolute elevation and relative elevation for each land use type in 2015 were also evaluated (Figure 5a). First, similar proportions of cropland, woodland, and grassland were distributed in each grade of absolute/relative elevation. Cropland in the fourth (C4) and fifth (C5) grades of relative elevation was in greater proportion than that of absolute elevation, while cropland in $\mathrm{C} 1$ and $\mathrm{C} 2$ of relative elevation was a lesser proportion than that of absolute elevation. The characteristics of grassland were just the opposite. Woodland in $\mathrm{C} 1, \mathrm{C} 2$, and $\mathrm{C} 5$ was a greater proportion of relative elevation than that of absolute elevation, while woodland in $\mathrm{C} 4$ was clearly a lower proportion of relative elevation than that of absolute elevation. Second, the proportions of water body, built-up land, and unused land in $\mathrm{C} 1$ of relative elevation were significantly larger than those of absolute elevation. The proportions of built-up land and unused land in C3 of relative elevation were significantly less than those of absolute elevation. Built-up land was mainly distributed in $\mathrm{C} 1$, accounting for $68.83 \%$ of the absolute elevation classification and $84.72 \%$ of the relative elevation classification.

(a)

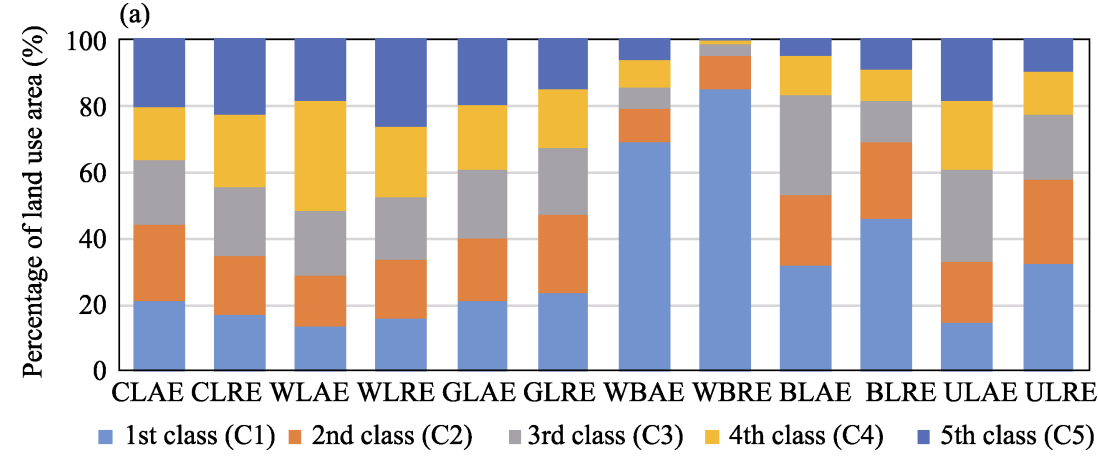

(b)

Land use types with absolute elevation and relative elevation

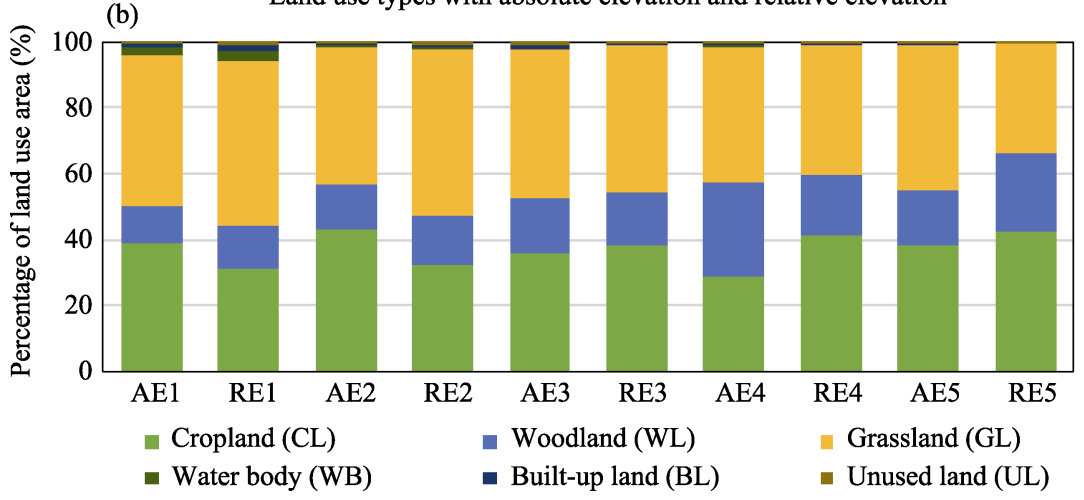

Classification of absolute elevation and relative elevation

Figure 5 Structure of land use with absolute elevation and relative elevation in the loess hilly region of northern Shaanxi Province in 2015

Note: abbreviations are defined as the two letters indicating land use types and the last two letters indicating classification of absolute/relative elevation. CL, cropland; WL, woodland; GL, grassland; WB, water body; BL, built-up land; UL, unused land; AE, classification of absolute elevation; RE, classification of relative elevation. $\mathrm{AE} 1$, the first class of absolute elevation; RE1, the first class of relative elevation. 
The land use structure for different classifications of absolute elevation and relative elevation in 2015 were also evaluated (Figure 5b). Cropland and grassland were the major land use types in five classes, accounting for more than $80 \%$ of absolute and relative elevations. The exceptions, where they were proportionally lower, were the fourth grade of absolute elevation (AE4, 70.29\%) and fifth grade of relative elevation (RE5, 76.00\%). The proportions of cropland in AE1 and AE2 were larger than those in RE1 and RE2, while the proportions in AE3, AE4, and AE5 were less than those in RE3, RE4, and RE5. In comparison, the characteristics of grassland were just the opposite. The proportions of woodland in AE3 and AE4 were larger than those in RE3 and RE4, which were also opposite in other grades of elevation.

\subsection{Changes in land use without elevation}

According to the transition matrices for 1995-2000, 2000-2005, 2005-2010, and 2010-2015, the dominant land use types fluctuated across the four periods (Tables 2-5). Cropland increased by $0.04 \%$ during $1995-2000$, and decreased by $4.58 \%, 0.60 \%$, and $0.29 \%$ during 2000-2005, 2005-2010, and 2010-2015, respectively. Woodland increased by $0.55 \%, 9.87 \%$, and $1.37 \%$ in the first three periods, respectively, and decreased by $0.30 \%$ during 2010-2015. Grassland decreased by $0.37 \%, 0.04 \%$, and $0.59 \%$ during $1995-2000$, 2005-2010, and 2010-2015, respectively, and increased by $0.50 \%$ during 2000-2005. Finally, built-up land maintained an increasing trend, expanding by $5.29 \%, 13.49 \%, 2.38 \%$, and $77.88 \%$ in the four periods, respectively.

From the perspective of land-use conversion, the loess hilly region was subject to significant changes from 2000 to 2005 . Land-use conversion accounted for $2.49 \%$ of the total area. In this period, the main characteristics of land-use conversion were loss of cropland and gain of woodland. The net lost area of cropland accounted for $1.79 \%$ of the total area, mainly converting to woodland (42.59\% of the total converted area) and grassland $(30.98 \%)$. The net gain of woodland accounted for $1.54 \%$ of the total area, mainly converting from cropland $(42.59 \%)$ and grassland (19.60\%). Cropland transformed to woodland was primarily distributed in north Yan'an, and the converted grassland to grassland was mainly distributed in central Yan'an and northeast Yulin. Woodland converted from grassland was mainly distributed in northwest Yan'an (Figure 6b).

Table 2 Transitions in percentages of total land use observed in the loess hilly region of northern Shaanxi Province during 1995-2000 (\%)

\begin{tabular}{|c|c|c|c|c|c|c|c|c|c|c|}
\hline \multirow{2}{*}{ Year 1995} & \multicolumn{6}{|c|}{2000} & \multirow{2}{*}{$\begin{array}{c}\text { Total } \\
(1995)\end{array}$} & \multirow{2}{*}{ Loss } & \multirow{2}{*}{$\begin{array}{l}\text { Net gain } \\
\text { in } 2000\end{array}$} & \multirow{2}{*}{$\begin{array}{l}\text { Changes } \\
\text { in } 2000\end{array}$} \\
\hline & $\mathrm{CL}$ & WL & GL & WB & $\mathrm{BL}$ & UL & & & & \\
\hline CL & 38.98 & 0.02 & 0.03 & 0.00 & 0.01 & 0.05 & 39.09 & 0.11 & 0.01 & 0.04 \\
\hline WL & 0.02 & 15.44 & 0.01 & 0.00 & 0.00 & 0.00 & 15.48 & 0.03 & 0.09 & 0.55 \\
\hline GL & 0.09 & 0.10 & 43.68 & 0.00 & 0.01 & 0.01 & 43.89 & 0.21 & -0.16 & -0.37 \\
\hline WB & 0.01 & 0.00 & 0.00 & 0.66 & 0.00 & 0.00 & 0.68 & 0.02 & -0.01 & -1.80 \\
\hline BL & 0.00 & 0.00 & 0.00 & 0.00 & 0.33 & 0.00 & 0.33 & 0.00 & 0.02 & 5.29 \\
\hline UL & 0.00 & 0.00 & 0.00 & 0.00 & 0.00 & 0.53 & 0.53 & 0.01 & 0.06 & 10.46 \\
\hline Total (2000) & 39.10 & 15.56 & 43.73 & 0.67 & 0.35 & 0.59 & 100.00 & 0.37 & & \\
\hline Gain & 0.12 & 0.12 & 0.05 & 0.01 & 0.02 & 0.06 & 0.37 & & & \\
\hline
\end{tabular}

Note: The abbreviations "CL", "WL", "GL", "WB", "BL" and "UL" are defined in the note for Figure 5. 
Table 3 Transitions in percentages of total land use observed in the loess hilly region of northern Shaanxi Province during 2000-2005 (\%)

\begin{tabular}{|c|c|c|c|c|c|c|c|c|c|c|}
\hline \multirow{2}{*}{ Year 2000} & \multicolumn{6}{|c|}{2005} & \multirow{2}{*}{$\begin{array}{c}\text { Total } \\
(2000)\end{array}$} & \multirow{2}{*}{ Loss } & \multirow{2}{*}{$\begin{array}{c}\text { Net gain } \\
\text { in } 2005\end{array}$} & \multirow{2}{*}{$\begin{array}{l}\text { Change } \\
\text { in } 2005\end{array}$} \\
\hline & $\mathrm{CL}$ & WL & GL & WB & $\mathrm{BL}$ & UL & & & & \\
\hline $\mathrm{CL}$ & 37.23 & 1.06 & 0.77 & 0.00 & 0.04 & 0.00 & 39.10 & 1.87 & -1.79 & -4.58 \\
\hline WL & 0.00 & 15.55 & 0.01 & 0.00 & 0.00 & 0.00 & 15.56 & 0.01 & 1.54 & 9.87 \\
\hline GL & 0.06 & 0.49 & 43.15 & 0.00 & 0.01 & 0.02 & 43.73 & 0.58 & 0.22 & 0.50 \\
\hline WB & 0.01 & 0.00 & 0.00 & 0.65 & 0.00 & 0.00 & 0.67 & 0.01 & -0.01 & -1.03 \\
\hline $\mathrm{BL}$ & 0.00 & 0.00 & 0.00 & 0.00 & 0.35 & 0.00 & 0.35 & 0.00 & 0.05 & 13.49 \\
\hline UL & 0.00 & 0.00 & 0.01 & 0.00 & 0.00 & 0.57 & 0.59 & 0.02 & 0.00 & -0.15 \\
\hline Total (2005) & 37.31 & 17.10 & 43.94 & 0.66 & 0.40 & 0.59 & 100.00 & 2.49 & & \\
\hline Gain & 0.08 & 1.55 & 0.79 & 0.01 & 0.05 & 0.02 & 2.49 & & & \\
\hline
\end{tabular}

Note: The abbreviations "CL", "WL", "GL", "WB", "BL" and "UL" are defined in the note for Figure 5.

Table 4 Transitions in percentages of total land use observed in the loess hilly region of northern Shaanxi Province during 2005-2010 (\%)

\begin{tabular}{|c|c|c|c|c|c|c|c|c|c|c|}
\hline \multirow{2}{*}{ Year 2005} & \multicolumn{6}{|c|}{2010} & \multirow{2}{*}{$\begin{array}{c}\text { Total } \\
(2005)\end{array}$} & \multirow{2}{*}{ Loss } & \multirow{2}{*}{$\begin{array}{c}\text { Net gain } \\
\text { in } 2010\end{array}$} & \multirow{2}{*}{$\begin{array}{l}\text { Change } \\
\text { in } 2010\end{array}$} \\
\hline & $\mathrm{CL}$ & WL & GL & WB & $\mathrm{BL}$ & UL & & & & \\
\hline $\mathrm{CL}$ & 37.08 & 0.17 & 0.05 & 0.00 & 0.01 & 0.00 & 37.31 & 0.23 & -0.22 & -0.60 \\
\hline WL & 0.00 & 17.09 & 0.00 & 0.00 & 0.00 & 0.00 & 17.10 & 0.00 & 0.23 & 1.37 \\
\hline GL & 0.00 & 0.07 & 43.87 & 0.00 & 0.00 & 0.00 & 43.94 & 0.07 & -0.02 & -0.04 \\
\hline WB & 0.00 & 0.00 & 0.00 & 0.66 & 0.00 & 0.00 & 0.66 & 0.00 & 0.00 & 0.58 \\
\hline $\mathrm{BL}$ & 0.00 & 0.00 & 0.00 & 0.00 & 0.40 & 0.00 & 0.40 & 0.00 & 0.01 & 2.38 \\
\hline UL & 0.00 & 0.00 & 0.01 & 0.00 & 0.00 & 0.58 & 0.59 & 0.01 & 0.00 & -0.75 \\
\hline Total (2010) & 37.09 & 17.33 & 43.92 & 0.66 & 0.41 & 0.58 & 100.00 & 0.31 & & \\
\hline Gain & 0.00 & 0.24 & 0.06 & 0.01 & 0.01 & 0.00 & 0.31 & & & \\
\hline
\end{tabular}

Note: The abbreviations "CL", "WL", "GL", "WB", "BL" and "UL" are defined in the note for Figure 5.

Table 5 Transitions in percentages of total land use observed in the loess hilly region of northern Shaanxi Province during 2010-2015 (\%)

\begin{tabular}{|c|c|c|c|c|c|c|c|c|c|c|}
\hline \multirow{2}{*}{ Year 2010} & \multicolumn{6}{|c|}{2015} & \multirow{2}{*}{$\begin{array}{l}\text { Total } \\
(2010)\end{array}$} & \multirow{2}{*}{ Loss } & \multirow{2}{*}{$\begin{array}{l}\text { Net gain } \\
\text { in } 2015\end{array}$} & \multirow{2}{*}{$\begin{array}{l}\text { Changes } \\
\text { in } 2015\end{array}$} \\
\hline & $\mathrm{CL}$ & WL & GL & WB & $\mathrm{BL}$ & UL & & & & \\
\hline $\mathrm{CL}$ & 36.93 & 0.00 & 0.00 & 0.01 & 0.11 & 0.03 & 37.09 & 0.15 & -0.11 & -0.29 \\
\hline WL & 0.01 & 17.28 & 0.00 & 0.00 & 0.02 & 0.02 & 17.33 & 0.05 & -0.05 & -0.30 \\
\hline GL & 0.03 & 0.00 & 43.66 & 0.01 & 0.17 & 0.06 & 43.92 & 0.27 & -0.26 & -0.59 \\
\hline WB & 0.00 & 0.00 & 0.00 & 0.65 & 0.00 & 0.00 & 0.66 & 0.01 & 0.01 & 1.61 \\
\hline BL & 0.00 & 0.00 & 0.00 & 0.00 & 0.41 & 0.00 & 0.41 & 0.00 & 0.32 & 77.88 \\
\hline UL & 0.00 & 0.00 & 0.00 & 0.00 & 0.02 & 0.56 & 0.58 & 0.02 & 0.09 & 15.80 \\
\hline Total (2015) & 36.98 & 17.28 & 43.66 & 0.67 & 0.73 & 0.68 & 100.00 & 0.51 & & \\
\hline Gain & 0.04 & 0.00 & 0.01 & 0.02 & 0.32 & 0.11 & 0.51 & & & \\
\hline
\end{tabular}

Note: The abbreviations "CL", "WL", "GL", "WB", "BL" and "UL" are defined in the note for Figure 5. 
Table 6 Transitions in percentages of total land use observed in the loess hilly region of northern Shaanxi Province during 1995-2015 (\%)

\begin{tabular}{|c|c|c|c|c|c|c|c|c|c|c|}
\hline \multirow{2}{*}{ Year 1995} & \multicolumn{6}{|c|}{2015} & \multirow{2}{*}{$\begin{array}{c}\text { Total } \\
(1995)\end{array}$} & \multirow{2}{*}{ Loss } & \multirow{2}{*}{$\begin{array}{l}\text { Net gain } \\
\text { in } 2015\end{array}$} & \multirow{2}{*}{$\begin{array}{l}\text { Changes } \\
\text { in } 2015\end{array}$} \\
\hline & $\mathrm{CL}$ & $\mathrm{WL}$ & GL & WB & $\mathrm{BL}$ & UL & & & & \\
\hline $\mathrm{CL}$ & 36.75 & 1.24 & 0.85 & 0.01 & 0.16 & 0.07 & 39.09 & 2.33 & -2.11 & -5.40 \\
\hline WL & 0.03 & 15.39 & 0.02 & 0.00 & 0.02 & 0.02 & 15.48 & 0.09 & 1.80 & 11.65 \\
\hline GL & 0.17 & 0.65 & 42.78 & 0.02 & 0.19 & 0.08 & 43.89 & 1.11 & -0.22 & -0.51 \\
\hline WB & 0.02 & 0.00 & 0.01 & 0.64 & 0.01 & 0.00 & 0.68 & 0.04 & 0.00 & -0.67 \\
\hline $\mathrm{BL}$ & 0.00 & 0.00 & 0.00 & 0.00 & 0.33 & 0.00 & 0.33 & 0.00 & 0.39 & 117.62 \\
\hline UL & 0.01 & 0.00 & 0.01 & 0.00 & 0.02 & 0.50 & 0.53 & 0.03 & 0.14 & 26.77 \\
\hline Total (2015) & 36.98 & 17.28 & 43.66 & 0.67 & 0.73 & 0.68 & 100.00 & 3.61 & & \\
\hline Gain & 0.22 & 1.89 & 0.88 & 0.04 & 0.39 & 0.17 & 3.61 & & & \\
\hline
\end{tabular}

Note: The abbreviations "CL", "WL", "GL", "WB", "BL" and "UL" are defined in the note for Figure 5.

Land use also clearly changed over the 2010-2015 period, with land-use conversion accounting for $0.51 \%$ of the total area. The main characteristics of land-use conversion were gains in built-up land and unused land and losses of grassland, mainly distributing in northeast Yulin and central Yan'an (Figure 6d). Built-up land increased 77.88\%, and its net gain accounted for $0.32 \%$ of the total area, mainly converted from grassland $(33.78 \%)$ and cropland $(21.83 \%)$. Unused land increased $15.80 \%$, mainly converting from grassland $(11.14 \%)$ and cropland (6.57\%). Finally, the net loss of grassland accounted for $0.26 \%$ of the total area, mainly converted to built-up land (33.78\%) and cropland (21.83\%).

However, land use change accounted for only $0.37 \%$ and $0.31 \%$ of the total area during 1995-2000 and 2005-2010. During 2005-2010, the changing trends of land use continued 2000-2005. Increases in woodland were scattered across the area, while increases in grassland were mainly distributed in northeast Yulin (Figure 6c). Land-use conversion during 1995-2000 was characterized by losses of grassland $(0.16 \%$ of total area) and gains in woodland $(0.09 \%)$. Simultaneously, cropland decreased $(0.11 \%)$ and increased $(0.12 \%)$ almost equally. Increases in cropland were scattered in east and south Yan'an and northeast Yulin, while increased grassland and woodland were mainly distributed in northeast and south Yulin (Figure 6a).

For the entire study period, land use change accounted for $3.61 \%$ of the total area. The main characteristics of land-use conversion were losses of cropland and gains in woodland and built-up land. First, the net loss area of cropland accounted for $2.11 \%$ of total area, mainly converting to woodland $(34.39 \%)$ and grassland $(23.50 \%)$. The patterns of cropland transformed to woodland and grassland were similar to that during 2000-2005. Second, the net gains in woodland accounted for $1.80 \%$ of the total area, mainly converted from cropland (34.39\%) and grassland (18.02\%). The patterns of woodland transformed from cropland and grassland were also similar to those during 2000-2005. Third, the built-up land increased $117.62 \%$ and its net gain accounted for $0.39 \%$ of the total area, mainly converted from grassland $(5.32 \%)$. The pattern of built-up land transformed from grassland was similar to that during 2010-2015 (Figure 6e). 

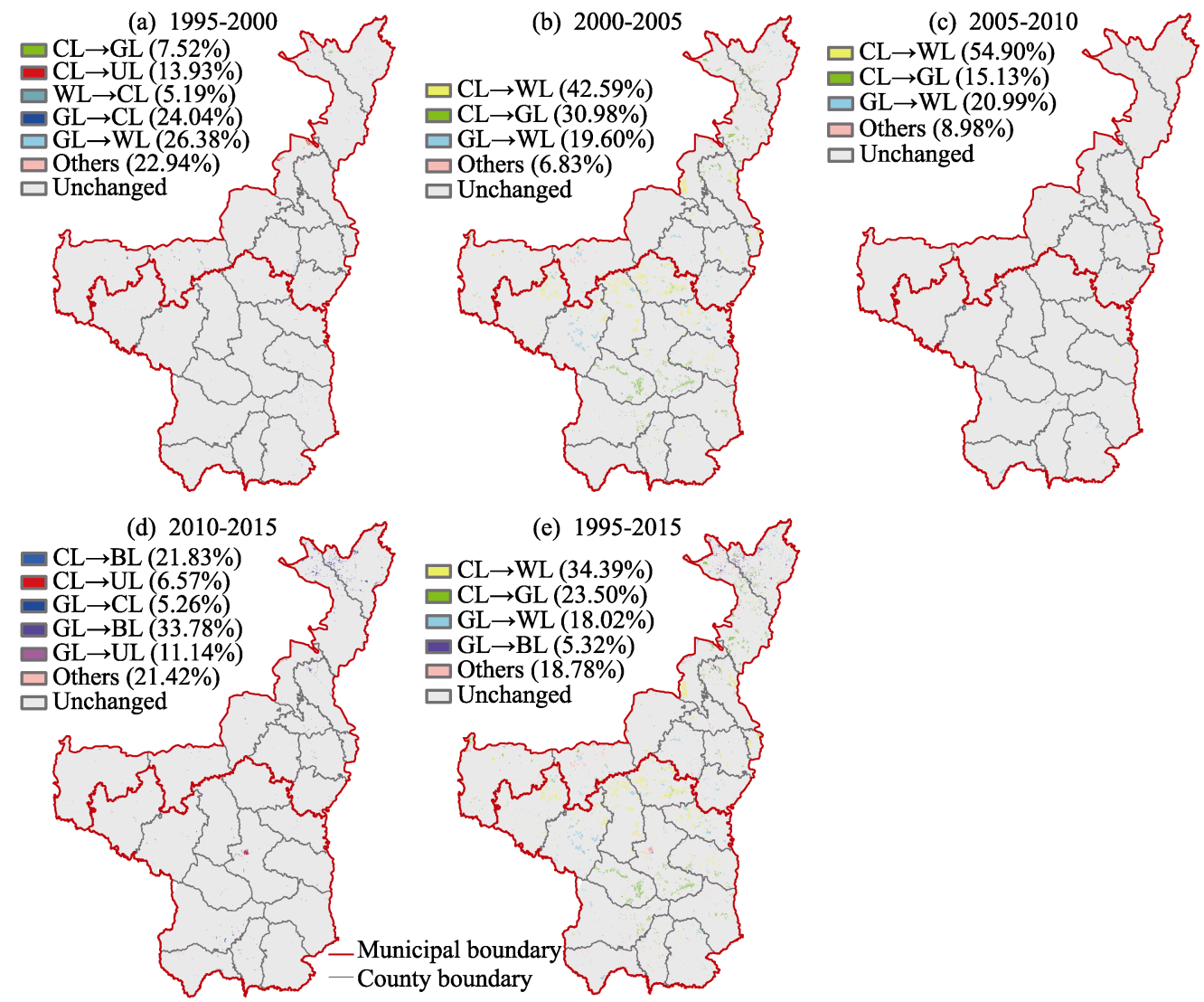

Figure 6 Patterns of land use change in the loess hilly region of northern Shaanxi Province during 1995-2000, 2000-2005, 2005-2010, 2010-2015, and 1995-2015

Note: The abbreviations "CL", "WL", "GL", "BL" and "UL" are defined in the note for Figure 5.

\subsection{Changes in land use with elevation}

Figure 7 shows land use change structure with absolute and relative elevation during 1995-2000, 2000-2005, 2005-2010, 2010-2015, and 1995-2015. For the entire study period, the proportions of each grade in the absolute/relative elevation classification were roughly equivalent. These were similar to those in the absolute elevation classification during 1995-2000 and 2000-2005 and to those in the relative elevation classification during 2000-2005 and 2005-2010. However, the proportions of C4 and C5 in the absolute/relative elevation classification were smaller in other periods. The proportions of $\mathrm{C} 1$ and $\mathrm{C} 2$ during 2005-2010 and that of C3 during 2010-2015 were larger in absolute elevation, while the proportion of C1 during 1995-2000 and that of C1 and C2 during 2010-2015 were larger in relative elevation.

The main types of land-use conversion were also evaluated based on the classifications of absolute/relative elevation. The five top-ranked land-use conversion types for both classifications were selected, and their grades of absolute/relative elevation and percentages of total change area were extracted (Table 7). The top ranked land-use conversion types for the two 


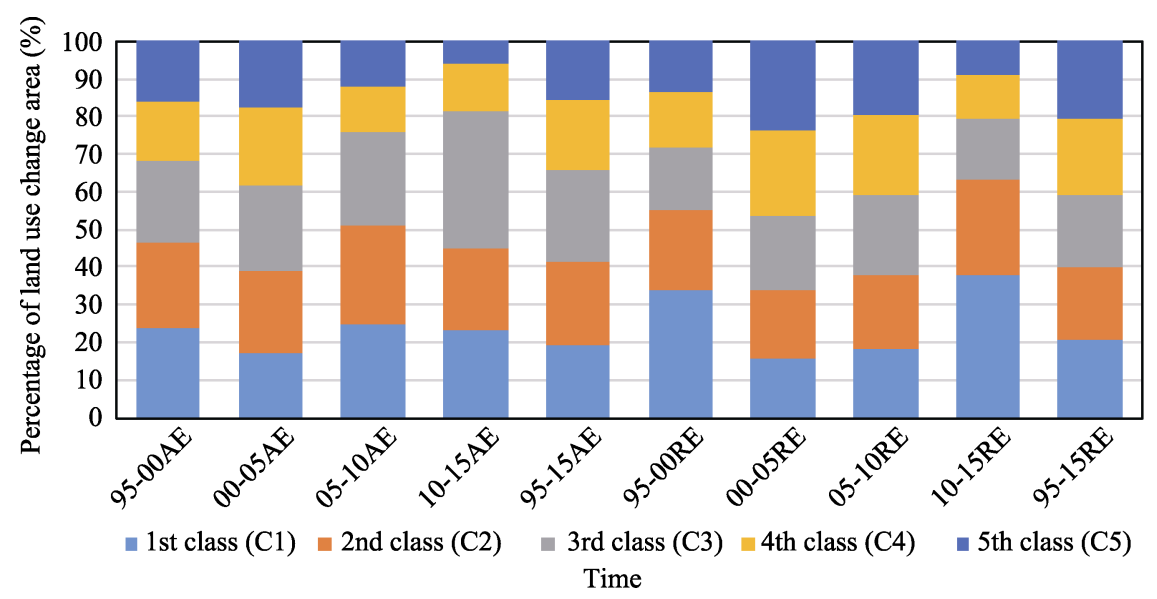

Figure 7 Structure of land use change with absolute elevation and relative elevation in the loess hilly region of northern Shaanxi Province during 1995-2000, 2000-2005, 2005-2010, 2010-2015, and 1995-2015

Note: the abbreviations are based on the period and classification of absolute/relative elevation, e.g. 95-00AE for 1995-2000 and AE indicates classification with absolute elevation; RE indicates classification with relative elevation.

classifications were generally similar across the five periods, as was the proportion of land use change. They were also consistent with the main land-use conversion types without elevation in Figure 6. However, the five top ranked land-use conversion types in the grades were different between the classifications for absolute and relative elevation, especially during 2000-2005, 2005-2010, and 2010-2015. To explore the difference, the structures of main land-use conversion types were plotted with the absolute and relative elevation classifications in these three periods (Figure 8).

During 2000-2005, the five top ranked land-use conversion types were found in all grades of absolute elevation, but only occurred in $\mathrm{C} 5, \mathrm{C} 4$, and $\mathrm{C} 3$ of relative elevation (Table 7). Structurally, the primary land-use conversion in the absolute/relative elevation classification was cropland transformed to woodland and grassland, which were distributed in higher grades of relative elevation. The proportions of cropland transformed to woodland in $\mathrm{C} 5$ and $\mathrm{C} 4$ of relative elevation were $30.50 \%$ and $24.37 \%$, higher than that of absolute elevation (22.00\% and $24.27 \%$ ), while those in $\mathrm{C} 1$ and $\mathrm{C} 2$ of relative elevation were $10.70 \%$ and $15.31 \%$, lower than those of absolute elevation (18.56\% and 17.64\%). Similarly, the proportions of cropland transformed to grassland in $\mathrm{C} 5$ and $\mathrm{C} 4$ of relative elevation were $21.50 \%$ and $24.76 \%$, higher than those of absolute elevation (4.07\% and $15.52 \%)$, while those in $\mathrm{C} 1$ and $\mathrm{C} 2$ of relative elevation were $12.84 \%$ and $18.56 \%$, lower than those of absolute elevation $(14.00 \%$ and $32.32 \%$ ) (Figure $8 \mathrm{a}$ ). In addition, the area of cropland transformed to woodland decreased progressively as the grade of relative elevation decreased, similar to cropland transformed to grassland in $\mathrm{C} 1-\mathrm{C} 4$ of relative elevation.

The distribution of land-use conversion in grades of absolute/relative elevation was generally balanced or decreasing during 2005-2010. The proportion of cropland transformed to woodland and grassland decreased in high grades of absolute/relative elevation. The proportions of cropland transformed to woodland in C5 and C4 of absolute elevation decreased to $20.07 \%$ and $9.29 \%$, and those of relative elevation decreased to $24.14 \%$ and $23.77 \%$, while 
those in $\mathrm{C} 1$ and $\mathrm{C} 2$ of absolute elevation increased to $25.60 \%$ and $26.93 \%$ and those of relative elevation increased to $13.42 \%$ and $17.50 \%$. Similarly, proportions of cropland transformed to grassland in $\mathrm{C} 5$ and $\mathrm{C} 4$ of absolute elevation decreased to $0.41 \%$ and $6.84 \%$, and those of relative elevation decreased to $12.71 \%$ and $19.71 \%$, while those in C1 and C2 of absolute elevation increased to $42.12 \%$ and $26.60 \%$, and those of relative elevation increased to $18.84 \%$ and $22.85 \%$ (Figure $8 \mathrm{~b}$ ). However, land-use conversion occurred in higher grades of relative elevation than those of absolute elevation. This difference was due to the higher proportions of cropland transformed to woodland in C5 and C4 of relative elevation $(24.14 \%$ and $23.77 \%)$ than those of absolute elevation $(20.07 \%$ and $9.29 \%)$ and higher proportions of cropland transformed to grassland in $\mathrm{C} 5$ and $\mathrm{C} 4$ of relative elevation (12.71\% and $19.71 \%)$ compared to absolute elevation $(0.41 \%$ and $6.84 \%)$. In addition, the area of cropland transformed to woodland decreased progressively as the grade of relative elevation decreased.

During 2010-2015, the five top ranked land-use conversion types were found in once grade higher of absolute elevation than in relative elevation (Table 7). Structurally, the main land-use conversion in the absolute/relative elevation classification also indicated that the area of increased built-up land and unused land decreased progressively as the grade of relative elevation increased. The proportions of built-up land transformed from cropland

Table 7 The five top ranked land-use conversion types in absolute and relative elevation in the loess hilly region of northern Shaanxi Province

\begin{tabular}{|c|c|c|c|c|c|c|}
\hline \multirow{2}{*}{ Time } & \multicolumn{3}{|c|}{ Absolute elevation } & \multicolumn{3}{|c|}{ Relative elevation } \\
\hline & Type & Class & $\%$ & Type & Class & $\%$ \\
\hline \multirow{5}{*}{ 1995-2000 } & $\mathrm{GL} \rightarrow \mathrm{WL}$ & $\mathrm{C} 5$ & 9.02 & $\mathrm{GL} \rightarrow \mathrm{WL}$ & $\mathrm{C} 1$ & 7.26 \\
\hline & $\mathrm{GL} \rightarrow \mathrm{CL}$ & $\mathrm{C} 1$ & 7.13 & $\mathrm{GL} \rightarrow \mathrm{WL}$ & $\mathrm{C} 2$ & 6.12 \\
\hline & $\mathrm{GL} \rightarrow \mathrm{WL}$ & $\mathrm{C} 1$ & 6.31 & $\mathrm{GL} \rightarrow \mathrm{CL}$ & $\mathrm{C} 5$ & 5.37 \\
\hline & $\mathrm{GL} \rightarrow \mathrm{CL}$ & $\mathrm{C} 2$ & 6.06 & $\mathrm{GL} \rightarrow \mathrm{CL}$ & $\mathrm{C} 2$ & 5.17 \\
\hline & $\mathrm{CL} \rightarrow \mathrm{UL}$ & $\mathrm{C} 3$ & 5.88 & $\mathrm{GL} \rightarrow \mathrm{WL}$ & $\mathrm{C} 3$ & 4.92 \\
\hline \multirow{5}{*}{ 2000-2005 } & $\mathrm{CL} \rightarrow \mathrm{GL}$ & $\mathrm{C} 3$ & 10.56 & $\mathrm{CL} \rightarrow \mathrm{WL}$ & $\mathrm{C} 5$ & 12.99 \\
\hline & $\mathrm{CL} \rightarrow \mathrm{WL}$ & $\mathrm{C} 4$ & 10.34 & $\mathrm{CL} \rightarrow \mathrm{WL}$ & $\mathrm{C} 4$ & 10.38 \\
\hline & $\mathrm{CL} \rightarrow \mathrm{GL}$ & $\mathrm{C} 2$ & 10.01 & $\mathrm{CL} \rightarrow \mathrm{WL}$ & $\mathrm{C} 3$ & 8.15 \\
\hline & $\mathrm{CL} \rightarrow \mathrm{WL}$ & $\mathrm{C} 5$ & 9.37 & $\mathrm{CL} \rightarrow \mathrm{GL}$ & $\mathrm{C} 4$ & 7.67 \\
\hline & $\mathrm{CL} \rightarrow \mathrm{WL}$ & $\mathrm{C} 1$ & 7.90 & $\mathrm{CL} \rightarrow \mathrm{GL}$ & $\mathrm{C} 3$ & 6.92 \\
\hline \multirow{5}{*}{ 2005-2010 } & $\mathrm{CL} \rightarrow \mathrm{WL}$ & $\mathrm{C} 2$ & 14.79 & $\mathrm{CL} \rightarrow \mathrm{WL}$ & C5 & 13.25 \\
\hline & $\mathrm{CL} \rightarrow \mathrm{WL}$ & $\mathrm{C} 1$ & 14.05 & $\mathrm{CL} \rightarrow \mathrm{WL}$ & $\mathrm{C} 4$ & 13.05 \\
\hline & $\mathrm{CL} \rightarrow \mathrm{WL}$ & $\mathrm{C} 5$ & 11.02 & $\mathrm{CL} \rightarrow \mathrm{WL}$ & $\mathrm{C} 3$ & 11.63 \\
\hline & $\mathrm{CL} \rightarrow \mathrm{WL}$ & $\mathrm{C} 3$ & 9.94 & $\mathrm{CL} \rightarrow \mathrm{WL}$ & $\mathrm{C} 2$ & 9.60 \\
\hline & $\mathrm{GL} \rightarrow \mathrm{WL}$ & $\mathrm{C} 3$ & 7.77 & $\mathrm{CL} \rightarrow \mathrm{WL}$ & $\mathrm{C} 1$ & 7.37 \\
\hline \multirow{5}{*}{ 2010-2015 } & $\mathrm{GL} \rightarrow \mathrm{BL}$ & $\mathrm{C} 3$ & 19.07 & $\mathrm{GL} \rightarrow \mathrm{BL}$ & $\mathrm{C} 1$ & 12.33 \\
\hline & $\mathrm{CL} \rightarrow \mathrm{BL}$ & $\mathrm{C} 3$ & 8.14 & $\mathrm{GL} \rightarrow \mathrm{BL}$ & $\mathrm{C} 2$ & 11.42 \\
\hline & $\mathrm{CL} \rightarrow \mathrm{BL}$ & $\mathrm{C} 1$ & 6.56 & $\mathrm{CL} \rightarrow \mathrm{BL}$ & $\mathrm{C} 1$ & 8.90 \\
\hline & $\mathrm{GL} \rightarrow \mathrm{BL}$ & $\mathrm{C} 2$ & 6.13 & $\mathrm{GL} \rightarrow \mathrm{BL}$ & $\mathrm{C} 3$ & 6.55 \\
\hline & $\mathrm{GL} \rightarrow \mathrm{UL}$ & $\mathrm{C} 1$ & 4.59 & $\mathrm{CL} \rightarrow \mathrm{BL}$ & $\mathrm{C} 2$ & 5.65 \\
\hline \multirow{5}{*}{ 1995-2015 } & $\mathrm{CL} \rightarrow \mathrm{GL}$ & $\mathrm{C} 3$ & 7.97 & $\mathrm{CL} \rightarrow \mathrm{WL}$ & C5 & 10.13 \\
\hline & $\mathrm{CL} \rightarrow \mathrm{WL}$ & $\mathrm{C} 4$ & 7.66 & $\mathrm{CL} \rightarrow \mathrm{WL}$ & $\mathrm{C} 4$ & 8.29 \\
\hline & $\mathrm{CL} \rightarrow \mathrm{WL}$ & $\mathrm{C} 5$ & 7.43 & $\mathrm{CL} \rightarrow \mathrm{WL}$ & $\mathrm{C} 3$ & 6.64 \\
\hline & $\mathrm{CL} \rightarrow \mathrm{GL}$ & $\mathrm{C} 2$ & 7.28 & $\mathrm{CL} \rightarrow \mathrm{GL}$ & $\mathrm{C} 4$ & 5.65 \\
\hline & $\mathrm{CL} \rightarrow \mathrm{WL}$ & $\mathrm{C} 1$ & 6.72 & $\mathrm{CL} \rightarrow \mathrm{WL}$ & $\mathrm{C} 2$ & 5.35 \\
\hline
\end{tabular}

Note: The abbreviations "CL", "WL", "GL", "BL" and "UL" are defined in the note for Figure 5. 
decreased from $40.79 \%$ in $\mathrm{C} 1$ to $5.93 \%$ in $\mathrm{C} 5$, those of built-up land transformed from grassland decreased from $36.49 \%$ in $\mathrm{C} 1$ to $1.80 \%$ in $\mathrm{C} 5$, and those of unused land transformed from grassland decreased from $36.37 \%$ in $\mathrm{C} 1$ to $7.96 \%$ in C5 (Figure 8c). Structurally, increases in unused land from grassland in absolute elevation classification were similar to those in relative elevation. From the perspective of absolute elevation, the proportion of unused land transformed from grassland also decreased from $36.37 \%$ in $\mathrm{C} 1$ to $7.96 \%$ in $\mathrm{C} 5$, but excluded $\mathrm{C} 4$.

\section{Discussion}

\subsection{Drivers of land use change}

Using these results, this study then evaluated the characteristics of land use change in the loess hilly region of northern Shaanxi Province in the four study periods. During 1995-2010, increases in cropland were mainly scattered in eastern and southern Yan'an and northeastern Yulin; increases in grassland and woodland were mainly distributed in northeast and southern Yulin. During 2000-2005 and 2005-2010, decreases in cropland and increases in woodland were mainly distributed in central and northern Yan'an City and northeastern Yulin. During 2010-2015, increases in built-up land and decreases in grassland were mainly found in northeastern Yulin. Land use changes were in 2000-2005 and 2010-2015 and were consistent with the spatio-temporal features of ecological construction policy and urbanization, also affected by climate change, which we describe as follows.

Ecological construction policy. In 1978, the Three-North Shelterbelt System project was initiated. The Mu Us Sandy Land Shelterbelt System and Loess Plateau Shelterbelt System were two key sub-projects. Significant achievements were made in sand control in the $\mathrm{Mu}$ Us Sandy Land using innovations such as afforestation and water conservation with extensive social participation (Li et al., 2017). During 1995-2000, increases in woodland and grassland occurred mainly in Yulin. However, the loess hilly-gully region in the south of northern Shaanxi still showed sporadic expansion of cropland because of competition between woodland, cropland, and farmers' livelihoods, which were not effectively guaranteed. In 1999, China began the Grain for Green Project (GGP), the largest and most effective ecological construction project implemented (Lü et al., 2012; Chen et al., 2015; Wang et al., 2015). Shaanxi Province, as a pilot location, took the lead in conducting this project. The loess hilly-gully region in northern Shaanxi was a key area for implementing the GGP (Cao et al., 2018). Driven by the GGP, reductions in cropland and increases in woodland were obvious across the whole area of northern Shaanxi in 2000-2005 and 2005-2010.

Urbanization. Northern Shaanxi Province is an important energy chemical base in China and located in the core of China's national urban agglomeration of Hu-Bao-E-Yu. In the 12th Five-Year Plan (2011-2015), Yan'an and Yulin have formulated policies to expand the central city, strengthen the county town, expand the county scale, and actively guide the population transfer to the urban center. During 2010-2015, the urban population increased 503,400, and the urbanization rate increased $8.14 \%$. According to major function oriented zoning, the key development-oriented zones mainly included six districts and counties in the northwest of Yulin City (Yuyang, Shenmu, Fugu, Hengshan, Jingbian, and Dingbian) and three districts 

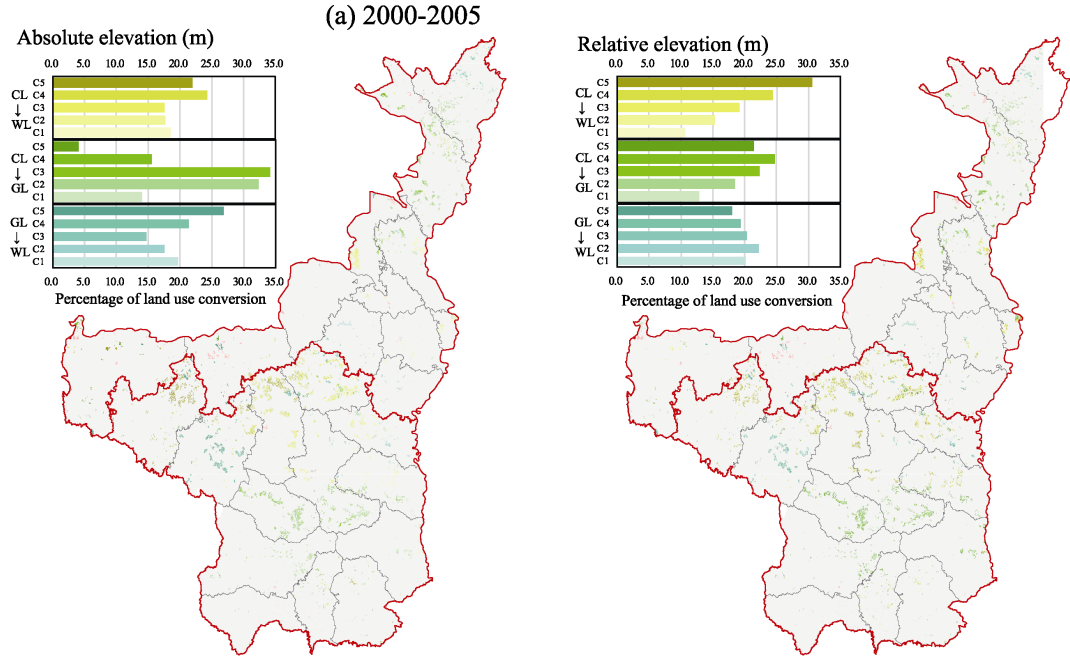

(b) $2005-2010$
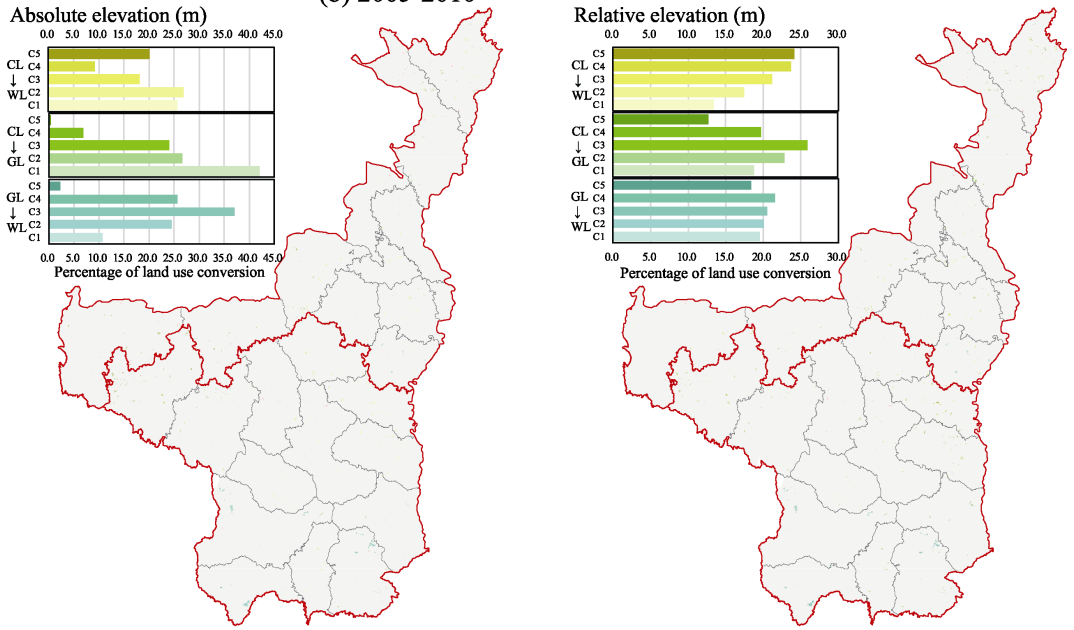

(c) $2010-2015$
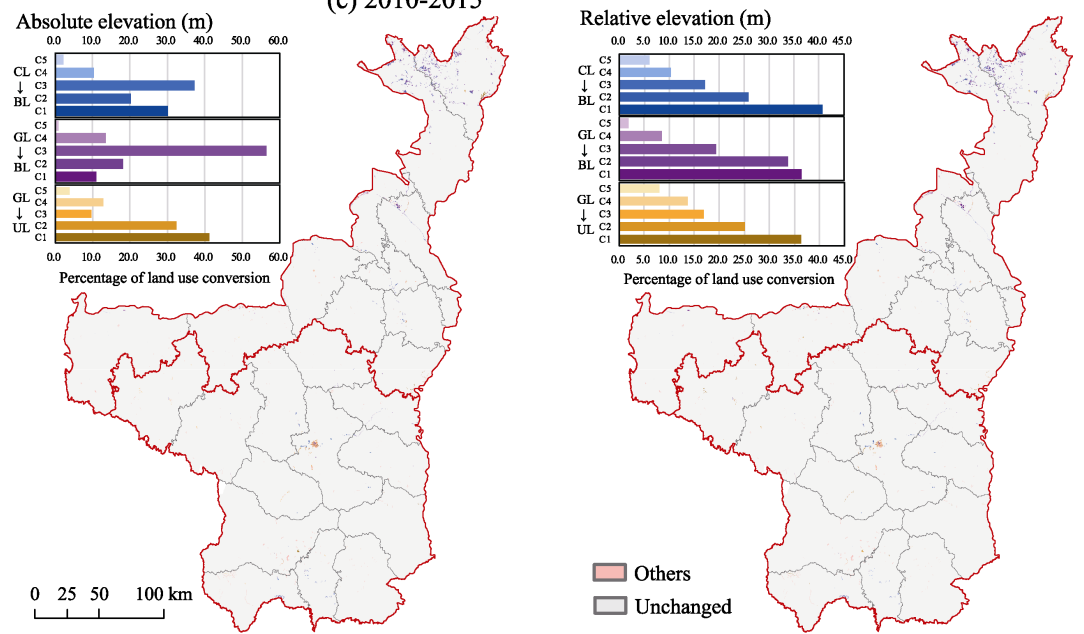

Figure 8 Vertical distribution of main land-use conversion types with two classifications of absolute elevation and relative elevation in the loess hilly region of northern Shaanxi Province during 2000-2005, 2005-2010 and 2010-2015 Note: The abbreviations "CL", "WL", "GL", "BL" and "UL" are defined in the note for Figure 5 and abbreviations for "C1", "C2", "C3"," "C4" and "C5" are defined in the note for Figure 7. 
and counties in the center of Yan'an City (Baota, Ganquan, and Ansai). In our study area, the increases in built-up land were mainly distributed in Fugu, Shenmu, and Baota during 2010-2015. To adapt to the urbanization process, Yan'an City also adopted a land creation project (Liu and Li, 2014), which results in the increase in unused land in Baota.

Climate change. Water resources are an important limiting factor for vegetation growth in the loess hilly region (Xin et al., 2008). Precipitation in most of the study area was more than $400 \mathrm{~mm}$. By analyzing changes in NDVI during 2000-2013, Cao et al. (2018) found vegetation restoration was concentrated in areas where precipitation was greater than 400 $\mathrm{mm}$. Moreover, the Loess Plateau presented a wetting trend after 2000 (Wang et al., 2012; Cao et al., 2018), partly inducing an increase in grassland and woodland. However, over the past three decades, the comprehensive effect of temperature, precipitation, and solar radiation has shown little impact on vegetation greening or browning trends (Liu et al., 2018b).

\subsection{Comparing absolute and relative elevation}

Elevation can affect the degree of land use difficulty, patterns, and utilization intensity by influencing climate, soil quality, and accessibility. Li et al. (2016) analyzed the relationship between land use change and absolute elevation in the Loess Plateau from 1986 to 2010. The authors found that land use change primarily occurred below $1600 \mathrm{~m}$, and the reduction in cropland and unused land and increase in woodland primarily occurred at 800-1600 m. Similarly, this study found a reduction in cropland and increase in woodland mainly between $1000 \mathrm{~m}$ and $1400 \mathrm{~m}$ during 2005-2010 in northern Shaanxi.

From the national or regional scale, absolute elevation has a greater impact on land use. However, at the provincial or smaller scale, the role of absolute elevation gradually declines, especially in the loess hilly and gully regions of northern Shaanxi. There are similar patterns of land use in the upper and lower reaches of the gully. Most land use models are three-dimensional soil and water protection agricultural models according to the height of the terrain, and residential land is mainly distributed at lower elevations (Liu et al., 2006). Therefore, in our study area, regardless of location upstream or downstream, the determinant of land use is relative elevation. Classifications of absolute elevation presented continuous nested partition features, and that of relative elevation presented parallel distribution features along the valley (Figure 3). Classifications based on relative elevation could improve the accuracy of elevation grading compared to absolute elevation. Coupled analysis of relative elevation and land use showed that the reduction in cropland and increase in woodland and grassland driven by the GGP was primarily found between relative elevations of 20-130 m.

Concurrently, we note that relative elevation had a greater impact on land use distribution and change only at the small to medium scale and with relatively rugged topographic relief. Future studies should analyze coupled effects on a larger scale and explore the grading points of absolute elevation and relative elevation. The slope and position of the terrain are also important factors affecting land use. However, due to the limitation of geomorphological feature extraction and analysis methods at large scale, this study only analyzed land use change based on classification of relative elevation. Perfecting the geomorphological characteristics analysis and extraction will be a priority in future research. In addition, although hills and gullies are widely distributed, there are different landform types in northern Shaanxi. For example, the wind-sand grass shoal area with relatively rugged topographic 
relief is distributed in the northwest. A comparative analysis of different landform types in the future work should reveal land use distribution and change features in different landform types. Finally, the spatial resolution of the land use datasets may affect the accuracy of coupled analysis of land use change and relative elevation, even though the CLUDs are the most complete sequence, with the highest precision and best quality available.

\section{Conclusions}

To explore the vertical distributions of land-use conversion in the loess hilly region of northern Shaanxi Province, this study classified absolute/relative elevation using the HAND index and analyzed land use change characteristics based on these classifications. The main findings are as follows.

First, the spatial pattern of absolute elevation showed that valleys had a nested distribution, while the spatial patterns of relative elevation showed valleys with a densely parallel distribution. Higher absolute elevation was concentrated in the west, but higher relative elevation was distributed in northwestern and eastern parts of Yan'an. The classifications of absolute and relative elevation showed a distribution with a similar proportion of each relative elevation grade in each absolute elevation grade.

Second, of the six land use types, cropland, woodland, and grassland were distributed evenly in each grade of absolute/relative elevation, while water body, built-up land, and unused land were more likely to spread to a lower grade of relative elevation than that of absolute elevation. The built-up land distributed in $\mathrm{C} 1$ accounted for $68.83 \%$ of the absolute elevation classification and $84.72 \%$ of the relative classification.

Third, over the entire $1995-2015$ study period, $3.61 \%$ of the loess hilly region of northern Shaanxi showed land-use conversion, with the most significant phenomenon occurring over 2000-2005 (2.49\% of the total area) compared to the other four five-year periods. The main characteristics of land-use conversion were losses of cropland $(2.11 \%$ of total area) and gains in woodland (1.80\% of total area) and built-up land ( $0.39 \%$ of total area and $117.62 \%$ increase).

Finally, land-use conversion showed an apparently stepped distribution with relative elevation classification, suitable for revealing vertical distributions of land-use conversion in the loess hilly region. The area of cropland transformed to woodland increased progressively from $10.07 \%$ in $\mathrm{C} 1$ of relative elevation to $30.50 \%$ in C5 during 2000-2005. In comparison, the proportional area of built-up land transformed from cropland decreased progressively from $40.79 \%$ in $\mathrm{C} 1$ to $5.93 \%$ in C5 during 2010-2015. Cropland transformed to woodland was mainly distributed at high grades of relative elevation, decreasing with decreases in grades. In comparison, built-up land transformed from cropland and grassland was mainly distributed in the low grade relative elevation, decreasing with increases in grades. Cropland transformed to woodland was found at lower grades of relative elevation with the implementation of the GGP. Therefore, it is better to analyze the vertical distribution of land-use conversion using relative elevation classification in hilly regions.

\section{Acknowledgements}

The authors thank Prof. Chengzhi Qin and Dr. Liangjun Zhu for the guidance and support on the AutoFuzSlpPos algorithm. 


\section{References}

Bai Jianjun, Bai Jiangtao, Wang Lei, 2014. Spatio-temporal change of vegetation NDVI and its relations with regional climate in northern Shaanxi Province in 2000-2010. Scientia Geographica Sinica, 34(7): 882-888. (in Chinese)

Cao Zhi, Li Yurui, Liu Yansui et al., 2018. When and where did the Loess Plateau turn "green"? Analysis of the tendency and breakpoints of the normalized difference vegetation index. Land Degradation \& Development, 29: $162-175$.

Chang Yue, Hou Kang, Li Xuxiang et al., 2018. Review of land use and land cover change research progress. IOP Conference Series: Earth and Environmental Science, 113: 012087.

Chen Guojie, 2007. Some considerations on strategy of development of mountain regions of China. Bulletin of Chinese Academy of Sciences, 22(2): 126-131. (in Chinese)

Chen Yiping, Wang Kaibo, Lin Yishan et al., 2015. Balancing green and grain trade. Nature Geoscience, 8: 739-741.

de Lollo J A, Marteli A N, Lorandi R, 2019. Flooding susceptibility identification using the HAND algorithm tool supported by land use/land cover data. In: IAEG/AEG Annual Meeting Proceedings, San Francisco, California, 2018, 2: 107-112.

Han Jianping, Jia Ningfeng, 2010. Relationship between topographic factor and land use: A case study of Zhuanyaogou watershed. Chinese Journal of Eco-Agriculture, 18(5): 1071-1075. (in Chinese)

Huang Shoubo, 1986. Advance in the investigation of the topographical microclimate in China (sum up). Geographical Research, 5(2): 90-101. (in Chinese)

Kumar R S, Chinnaiah K, Kumar B V S, 2012. Detection studies of land use/land cover changes in Sandur Taluk, Bellary district, Karnataka, India, using remote sensing and GIS techniques. International Journal of Earth Sciences \& Engineering, 5(1): 133-138.

Li Jingjing, Li Zhi, Lü Zhemin, 2016. Analysis of spatiotemporal variations in land use on the Loess Plateau of China during 1986-2010. Environmental Earth Sciences, 75(11): 997.

Li Wangjun, Lü Changhe, 2015. Aridity trend and response to vegetation restoration in the loess hilly region of northern Shaanxi Province. Journal of Geographical Sciences, 25(3): 289-300.

Li Xiubin, 2002. Explanation of land use changes. Progress in Geography, 21(3): 195-203. (in Chinese)

Li Yurui, Cao Zhi, Long Hualou et al., 2017. Dynamic analysis of ecological environment combined with land cover and NDVI changes and implications for sustainable urban-rural development: The case of Mu Us Sandy Land, China. Journal of Cleaner Production, 142: 697-715.

Liu Jiyuan, Liu Mingliang, Zhuang Dafang et al., 2003. Study on spatial pattern of land-use change in China during 1995-2000. Science in China (Series D), 46(4): 373-384.

Liu Jiyuan, Zhang Zengxiang, Xu Xinliang et al., 2010. Spatial patterns and driving forces of land use change in China during the early 21st century. Journal of Geographical Sciences, 20(4): 483-494.

Liu Yansui, 2018. Introduction to land use and rural sustainability in China. Land Use Policy, 74(5): 1-4.

Liu Yansui, Fang Fang, Li Yuheng, 2014. Key issues of land use in China and implications for policy making. Land Use Policy, 40(4): 6-12.

Liu Yansui, Guo Yanjun, Li Yurui et al., 2015. GIS-based effect assessment of soil erosion before and after gully land consolidation: A case study of Wangjiagou project region, Loess Plateau. Chinese Geographical Science, 25: 137-146.

Liu Yansui, Jin Xiaoyan, Hu Yecui, 2006. Study on the pattern of rural distinctive eco-economy based on land resources: A case study of Suide county in Loess Hilly Areas. Journal of Natural Resources, 21(5): 738-745. (in Chinese)

Liu Yansui, Li Yuheng, 2014. China's land creation project stands firm. Nature, 511: 410.

Liu Yansui, Li Yuheng, 2017. Revitalize the world's countryside. Nature, 548(7667): 275-277.

Liu Yansui, Yang Yuanyuan, Li Yurui et al., 2017. Conversion from rural settlements and arable land under rapid urbanization in Beijing during 1985-2010. Journal of Rural Studies, 51: 141-150. 
Liu Yansui, Zhang Ziwen, Zhou Yang, 2018a. Efficiency of construction land allocation in China: An econometric analysis of panel data. Land Use Policy, 74: 261-272.

Liu Zhengjia, Liu Yansui, Li Yurui, 2018b. Anthropogenic contributions dominate trends of vegetation cover change over the farming-pastoral ecotone of northern China. Ecological Indicators, 95: 370-378.

Liu Zhengjia, Liu Yansui, Li Yurui, 2019. Extended warm temperate zone and opportunities for cropping system change in the Loess Plateau of China. International Journal of Climatology, 39: 658-669.

Lü Yihe, Fu Bojie, Feng Xiaoming et al., 2012. A policy-driven large scale ecological restoration: Quantifying ecosystem services changes in the Loess Plateau of China. PLoS One, 7: e31782.

Ning Jia, Liu Jiyuan, Kuang Wenhui et al., 2018. Spatiotemporal patterns and characteristics of land-use change in China during 2010-2015. Journal of Geographical Sciences, 28(5): 547-562.

Nobre A D, Cuartas L A, Hodnett M et al., 2011. Height above the nearest drainage: A hydrologically relevant new terrain model. Journal of Hydrology, 404(1/2): 13-29.

Park T, Lee W K, Woo S Y et al., 2011. Assessment of land-cover change using GIS and remotely-sensed data: A case study in Ain Snoussi area of northern Tunisia. Forest Science and Technology, 7(2): 75-81.

Qin C Z, Gao H R, Zhu L J et al., 2018. Spatial optimization of watershed best management practices based on slope position units. Journal of Soil and Water Conservation, 73(5): 504-517.

Qin Chengzhi, Zhu Axing, Shi Xun et al., 2009. Quantification of spatial gradation of slope positions. Geomorphology, 110: 152-161.

Reis S, 2008. Analyzing land use/land cover changes using remote sensing and GIS in Rize, North-East Turkey. Sensors, 8(10): 6188-6202.

Rennó C D, Nobre A D, Cuartas L A et al., 2008. HAND, a new terrain descriptor using SRTM-DEM: Mapping terra-firme rainforest environments in Amazonia. Remote Sensing of Environment, 112(9): 3469-3481.

Tang Guoan, Yang Xin, 2015. ArcGIS Geographic Information System Spatial Analysis Experiment Tutorial. 2nd ed. Beijing: Science Press. (in Chinese)

Tarboton D G, 1997. A new method for the determination of flow directions and contributing areas in grid digital elevation models. Water Resources Research, 33(2): 309-319.

Tesfa T K, Tarboton D G, Watson D W et al., 2011. Extraction of hydrological proximity measures from DEMs using parallel processing. Environmental Modelling \& Software, 26: 1696-1709.

Wang Qixiang, Fan Xiaohui, Qin Zuodong et al., 2012. Changes trends of temperature and precipitation in the Loess Plateau region of China, 1961-2010. Global and Planetary Change, 92/93: 138-147.

Wang Shuai, Fu Bojie, Piao Shilong et al., 2015. Reduced sediment transport in the Yellow River due to anthropogenic changes. Nature Geoscience, 9: 38-41.

Xin Zhongbao, Xu Jiongxin, Zheng Wei, 2008. Spatiotemporal variations of vegetation cover on the Chinese Loess Plateau (1981-2006): Impacts of climate changes and human activities. Science in China Series D: Earth Sciences, 1: 67-78.

Zhang Baoqing, Wu Pute, Zhao Xining et al., 2012. Changes in vegetation condition in areas with different gradients (1980-2010) on the Loess Plateau, China. Environmental Earth Sciences, 68(8): 2427-2438.

Zhou Yi, Tang Guoan, Yang Xin et al., 2010. Positive and negative terrains on northern Shaanxi Loess Plateau. Journal of Geographical Sciences, 20(1): 64-76.

Zhu Liangjun, Zhu Axing, Qin Chengzhi et al., 2018. Automatic approach to deriving fuzzy slope positions. Geomorphology, 304: 173-183. 